\title{
Innovation Types and Regulation: the Regulatory Framing of Nanotechnology as "Incremental" or "Radical" Innovation
}

\author{
Stijn SMISMANS* and Elen STOKES**
}

\begin{abstract}
The regulatory literature has long been concerned with the challenges of technological innovation, yet it says relatively little about what we understand as "innovative" and how innovation "types" impact on regulation. This article unpacks the concept of "innovation" and analyses its significance for the development of regulatory strategy. It shows that innovation types - such as "incremental" and "radical" innovation - are not clear-cut, but involve differences of interpretation. This interpretive flexibility makes them powerful discursive resources in regulatory decision-making. Through a study of the EU's regulation of nanotechnology, the article shows how arguments of "incremental" and "radical" innovation can be mobilised to very different effect. These different ways of conceptualising new technology affect decisions on: (i) the desirability of legislative reform; (ii) the evidence-base for regulation; and (iii) the use of the precautionary principle. The study also shows how the framing of technology as "incrementally" innovative can contribute to a strategy of "deliberate regulatory ignorance". The article concludes by arguing that the incremental/radical distinction can be put to more positive use, so that regulatory choices take account of the different techno-scientific and socio-economic dimensions of innovation.
\end{abstract}

\section{INTRODUCTION}

The relationship between innovation and regulation has attracted significant policy and academic attention in recent years. This is in part because of increased political attention on the role of techno-scientific progress in achieving social and economic betterment, but also because of public controversies concerning the regulation of particular high-tech products and processes. Typically, the focus is on how regulation might respond to the risks involved in scientific and technological innovation by controlling potential harms to human health or the environment. While the types of risks and reasons for intervening

\footnotetext{
* Stijn Smismans is Professor of EU Law at the School of Law and Politics and Director of the Centre for European Law and Governance at Cardiff University.

** Elen Stokes is Professor of Energy and Environmental Law at Birmingham Law School. We are grateful to Emanuela Bozzini, Cristie Ford, Rachel Minto, Carlo Petrucci, Nicky Priaulx, Keith Syrett and the anonymous referees for their helpful comments on an earlier draft. The research leading to this article has received funding from the European Research Council under the European Union's Seventh Framework Programme (FP/2007-2013) / ERC Grant Agreement n. 313642-LASI ("Law, science and interests in European policy-making").
} 
may vary, there is a general consensus that risk has become "the central organising principle in regulation and public service delivery". ${ }^{1}$ Although this is not unique to the regulation of new technology, it may indeed be exacerbated by a perceived need to minimise or eliminate risks created by technological advances.

This article looks beyond the risk regulation literature to the broader literature on innovation, in order to bring constructive new insights to a critique of EU regulatory policy. In regulatory scholarship, "innovation" is often used as an umbrella term for a range of phenomena with which regulation must contend, but relatively little is said about what we understand as technologically "innovative" or whether we can distinguish between different types and degrees of innovation for the purpose of regulation. Even less attention is paid to "innovation" as a discursive practice by which regulation is framed and legitimated. This article shows how different innovation "types" can be important strategic resources, in the sense that they actively shape regulatory responses to new technology.

The article is structured as follows. Section II surveys the different innovation "types" in the innovation literature and explains the basic conceptual distinction between "radical" and "incremental" innovation. This literature shows that innovation types are not clear-cut, but involve differences of both degree and interpretation. Section III investigates, from a theoretical perspective, the regulatory consequences of dealing with radical or incremental innovation. Although the distinction has its roots in product management and organisational theory, it nevertheless has purchase in decisions about regulation. We show that the distinction between "radical" and "incremental" innovation may impact on: (i) the desirability of a new legislative framework; (ii) the nature and extent of the evidence-base for regulation; and (iii) the use of the precautionary principle (PP).

Having dealt with the distinction from a theoretical perspective, we then analyse how the "radical versus incremental" dichotomy has played out in EU regulatory practice, using a case study of the EU's regulation of nanotechnology. Section IV examines whether the literature on nanotechnology defines this new technology as "radically" or "incrementally" innovative. We show not only how conceptualisations of nanotechnology as "radical" or "incremental" innovation have influenced the EU's regulatory approach, but also how the distinction is open to various interpretive possibilities and, as such, becomes part of the discursive politics of justifying different regulatory strategies. We demonstrate this discursive and strategic dimension by contrasting the regulatory responses of the European Commission and the European Parliament (Sections V and VI). Whereas the Commission has tended to treat nanotechnology as "incrementally" innovative and as not requiring specific regulatory provision, the Parliament has focused on the "radical" nature of the technology and the corresponding need for regulatory reform.

Exploring this further, we argue that the Commission's conceptualisation of nanotechnology as "incremental" innovation has enabled a strategy of wilful nonknowing or "deliberate regulatory ignorance". Here, we mean ignorance not only in the

1 J Black, "The Emergence of Risk-Based Regulation and the New Public Risk Management in the UK" (2005) Public Law 512, 512. Classic sociological works on the role of risk in modern society, for example as a systematic means of dealing with hazards induced by modernisation, include U Beck, Risk Society: Towards a New Modernity (Sage 1992); Peter L Bernstein, Against the Gods: The Remarkable Story of Risk (John Wiley \& Sons 1996); A Giddens, "Risk and Responsibility" (1999) 62(1) Modern Law Review 1. 
sense of knowledge deficits but also as an active construct. Through its narrow framing of nanotechnology of possible regulatory responses, the Commission has been able to avoid systematic engagement with broader questions such as the socio-economic implications of this particular technological development.

The case study shows how policymakers effectively frame innovation as "incremental" or "radical" as a means of steering regulatory responses in particular directions. We note, in this context, that the framing of a technology as "incrementally" innovative may be driven by political convenience, as it relieves policymakers of the need to seek further understanding of the wider social, economic and environmental implications of nanotechnology. In other words, the categorisation of innovation into certain "types" can be a powerful legitimating tool in justifying a particular course of regulatory action or inaction. By acknowledging that the incremental/radical distinction is not inevitable but depends, at least in part, on different institutional readings of a technology's "innovativeness", it is possible to see innovation "types" not just as objects of governance, but as instruments of governance. Moreover, we argue that the incremental/radical distinction could be put to more positive use by encouraging reflection on the different dimensions of innovation (techno-scientific and socioeconomic), and by ensuring that the range of issues and complexities is openly and systematically taken into account.

\section{InNOvation "Types"}

Much has been written about the role of regulation in responding to innovation. ${ }^{2}$ These works deal with different examples of innovation in different fields (e.g. biotechnology, financial markets) and together they draw a range of conclusions about how law and governance are or should be deployed in the solving of innovation-related problems. One of the big questions is whether regulatory responses are sufficient to deal with such rapidly evolving fields, however there has been little systematic investigation of how regulatory approaches may differ depending on the nature of the innovation. Notable exceptions include the work of Jasanoff on differences in the legal treatment of new technology depending on whether the technology is construed as "novel", "natural" or "normal", 3 and that of Ford on the idiosyncrasies and challenges of regulating "seismic" and "sedimentary" innovation in the financial sector. ${ }^{4}$ Building on this important and valuable research, we suggest that there is further work to be done to understand how innovation "types" contribute to the discursive politics of regulation in the EU. We pursue this line of inquiry, first by identifying different degrees of "innovativeness",

\footnotetext{
2 See e.g. RB Stewart, "Regulation, Innovation, and Administrative Law: A Conceptual Framework" (1981) 69(5) California Law Review 1256; S Jasanoff, Designs on Nature: Science and Democracy in Europe and the United States (Princeton University Press 2005); J Black, M Lodge, M Thatcher (eds) Regulatory Innovation: A Comparative Analysis (Edward Elgar 2006); GN Mandel, "Regulating Emerging Technologies" (2009) 1 Law, Innovation and Technology 75; R Brownsword and M Goodwin, Law and the Technologies of the Twenty-First Century: Text and Materials (Cambridge University Press 2012); C Ford, "Innovation-Framing Regulation" (2013) Annals of the American Academy of Political and Social Sciences 649.

3 S Jasanoff, "Ordering Life: Law and the Normalization of Biotechnology" (2001) XVII(62) Politeia 34; "Ordering Knowledge, Ordering Society" in S Jasanoff (ed.) States of Knowledge: the Co-Production of Science and Social Order (Routledge 2004) ch 2.

4 C Ford, Innovation and the State: Finance, Regulation, and Justice (Cambridge University Press 2017) (forthcoming).
} 
and then by focusing on how the distinction between "radical" and "incremental" innovation can influence regulation. Whereas previous work has analysed the discursive force of regulation in "normalising" radical innovation," we approach the issue the other way round, by examining the discursive force of innovation (and its various conceptualisations, e.g. incremental and radical) in shaping and sustaining particular regulatory responses.

Innovation studies have produced a rich body of theoretical and empirical research into the meaning of "innovation" in different contexts - such as business organisation and management, ${ }^{6}$ marketing, ${ }^{7}$ and product development. ${ }^{8}$ We do not detail that work here, but we will reflect on some of its general findings. A first point relates to how innovation is defined and by whom. Innovation implies novelty, but novelty can be determined from a range of different perspectives. A product or process may be new to the world, the industry, the scientific community, the marketplace, the firm, or the customer. ${ }^{9}$ Likewise, "novelty" may be present in any one of a number of different things - it may involve new products, service offerings or processes, new benefits, new patterns of consumption, new supply chains, new risks, or new functionalities, or all of these elements. ${ }^{10}$ It may take the form either of pioneering technological developments or new configurations of existing technologies. ${ }^{11}$ The scale at which innovation is assessed is also important, as it dictates whether innovation is understood in narrowly technical terms, ${ }^{12}$ or whether it encompasses a broader range of variables - including organisational, commercial and social innovations. ${ }^{13}$ Abernathy and Clark, for example, have drawn a distinction between innovation at the level of systems and procedures (called "architectural" innovation), which results in new systems of production and the creation of new linkages to markets and users, ${ }^{14}$ and innovation of a more precise kind (called "niche creation"), which involves refining products or processes to meet previously unmet consumer needs. ${ }^{15}$

A second observation is that "innovation" is a question of degree - and, even if there is little consensus on the appropriate terminology, it is commonly accepted that innovation works in shades of grey rather than black and white. Innovation is not simply a matter

5 Jasanoff, supra note 3.

6 E.g. MM Crossan and M Apaydin, "A Multi-Dimensional Framework of Organizational Innovation: A Systematic Review of the Literature" (2010) 47(6) Journal of Management Studies 1154.

7 E.g. J Hauser, JG Tellis and A Griffin, "Research on Innovation: A Review and Agenda for Marketing Science" (2006) 25(6) Marketing Science 687.

8 E.g. P Trott, Innovation Management and New Product Development (4th edn, Prentice Hall 2008).

9 R Garcia and R Calantone, "A Critical Look at Technological Innovation Typology and Innovativeness Terminology: A Literature Review” (2002) 19 Journal of Product Innovation Management 110.

10 OECD and Eurostat, Oslo Manuel: Guidelines for Collecting and Interpreting Innovation Data (OCED 2005).

11 GM Schmidt, "Low-End and High-End Encroachments for New Products" (2004) 8(2) International Journal of Innovation Management 167.

12 RR Nelson and N Rosenberg, "Technical Innovation and National Systems" in RR Neldon (ed.) National Innovation Systems: A Comparative Analysis (Oxford University Press 1993) ch 1.

13 JA Schumpeter, Business Cycles: A Theoretical, Historical and Statistical Analysis of the Capitalist Process (Martino Publishing 1939); S Isaksen and J Tidd, Meeting the Innovation Challenge: Leadership for Transformation and Growth (Wiley 2006).

14 WJ Abernathy and KB Clark, "Innovation: Mapping the Winds of Creative Destruction" (1985) 14 Research Policy 3, 7.

15 ibid 10. 
of "innovative or not", for some would argue that any change - to products, processes or services - involves innovation on some level. So the critical issue becomes "how innovative?" (not "whether innovative?"), which requires a framework for thinking about innovation along a sliding scale. Porter famously distinguished between "continuous" and "discontinuous" technological evolution in analysing product-market competition. ${ }^{16}$ Abernathy and Clark discussed the contrasts between "regular" and "revolutionary" innovation in established systems of production and marketing. "Regular" innovation involves change that builds cumulatively on established technical and production competences and is applied to existing markets and consumers. "Revolutionary" innovation, on the other hand, is fundamentally disruptive, involving radical market change and rendering technical and production facilities or resources obsolete. ${ }^{18}$ Anderson and Tushman drew a similar distinction between "revolutionary" and "stochastic" technological breakthroughs. ${ }^{19}$ Revolutionary breakthroughs involve "fundamentally different product forms that command a decisive cost, performance, or quality advantage over prior product forms". ${ }^{20}$ Examples include jet engines (rather than piston engines), and electronic typewriters (replacing mechanical typewriters). Accounts such as these suggest that innovation can be defined not just in narrowly technical terms, but also in terms of its broader societal implications - jet engines having reduced travel time and increased social mobility, and electronic typewriters bringing about greater speed and legibility in written communication.

As this sketch shows, the terminology ("disruptive", "sustaining", "discontinuous", "continuous", "radical", "incremental") is ready to hand but can have quite different connotations depending on context. Insofar as it is possible to draw general principles from this wide-ranging literature, it can be said that claims of "innovativeness" depend, at least in part, on differences of perspective and interpretation. Despite this interpretive flexibility, ontological distinctions continue to be drawn between "radical" and "incremental" innovation types (or their many variants) as a means of analysing the effects of innovation on, for example, firm performance and market structure. Yet, "radical" innovation and "incremental" innovation are more than ontological concepts; they are also important strategic and discursive resources. The remainder of the article looks at how interpretations of innovation as "radical" or "incremental" can be taken up in competing frames of policy discourse. As different ways of representing technological innovation, the labels "radical" and "incremental" can proliferate different policy or regulatory responses and have different political or strategic uses.

\section{Regulating "RADiCAL" OR "INCREMENTAL" InNOVATION}

From a regulatory perspective, we focus here on the common ground in the definitions provided in the literature, by considering innovation on a continuum between more

\footnotetext{
16 ME Porter, Competitive Advantage: Creating and Sustaining Superior Performance (First Free Press 1985).

17 Abernathy and Clark, supra note 14, 8-12.

18 ibid.

19 P Anderson and ML Tushman, "Technological Discontinuities and Dominant Designs: A Cyclical Model of Technological Change” (1990) 35 Administrative Science Quarterly 604.

20 ibid 607.
} 
"radical" (less "incremental") innovation and more "incremental" (less "radical") innovation. We consider that innovation may be "radical" for two main reasons: either due to the "technical" scientific novelty of a product or process or both, or because of its significant wider socio-economic implications. The two do not always go hand in hand. As has been noted, an "incremental" technical development may still have a major socioeconomic impact, for example, due to its creation of new markets, its promise of a "revolutionised" economy, or its bringing of new benefits to health and the environment. The converse is also true, since a "radical" technical development will not automatically or necessarily have a dramatic impact on society more generally.

It is useful to keep these different dimensions (techno-scientific; socio-economic) in mind when considering how the distinction between radical and incremental innovation may impact on regulatory choices. In this section we argue that the conceptualisation of innovation as "radical" or "incremental" may influence the regulatory approach in three main ways: as it relates to (i) legislative reform; (ii) evidence-based regulation; and (iii) the PP. Our analysis in this section is theoretical, in the sense that it independent of our subsequent case study on nanotechnology, but it is empirically embedded in the context of EU governance. While we identify some normative arguments (related to, for instance, democratic accountability and evidence-based policymaking) about how the "incremental"/"radical" distinction can inspire regulatory choices, we also stress that policymakers may rely on a more pragmatic and strategic use of the distinction.

\section{1. "Radical" versus "incremental" innovation and the desirability of a new legislative framework}

The overarching question to which commentators often return, is whether a newly emerging technology is so novel, so "radically different", that it has outstripped the capacity of existing regulation to deal with it. As case studies have shown, it will rarely (if ever) be the case that a technology is so new that there is no applicable law in the area. $^{21}$ It may be questioned, however, whether existing regulations are sufficiently well equipped to cope with the patterns and consequences of any given technological advance. Therefore, the question "how innovative?" is of central importance to decisions about regulation because the more "novel" a technology is deemed to be, the more likely it is to be "disconnected" from the regulatory framework, leaving policymakers and other stakeholders unable to say exactly how the regulation applies. ${ }^{22}$ So, where innovation is understood to be "radical" there may be calls for legislative reform. Conversely, it may be assumed that innovation labelled as "incremental" can be dealt under existing rules and regulations.

Indeed, a normative case can be made for dealing with "radical" innovation at the legislative level. Radical innovation will not always - or even usually - warrant an entirely new legislative framework or new legislative provisions. But, we would suggest,

21 See eg SCHER, SCENIHR, SCCS (2014) Opinion on Synthetic Biology I: Definition, adopted by the SCCS at their plenary on 23 September 2014, the SCENIHR at their plenary on 24 September 2014 and the SCHER by written procedure on 25 September 2014, 16.

22 Brownsword and Goodwin, supra note 2, 64-68. 
there are several reasons for ensuring that such decisions are at least discussed as part of the legislative process. Existing regulatory measures may be ill-suited to dealing with the risks, opportunities and other challenges associated with an emerging technology. Relying on "inherited" legislation - legislation designed before the latest technological development was envisaged or became available - can have its limitations. ${ }^{23}$ For example, the legislation may have gaps in content or be out of step with changing social norms. What is more, because "radical" innovation may bring about significant change not just in terms of technological production, performance or cost but also as regards broader social and political effects, and because difficult trade-offs may need to be made between competing values and interests, it is reasonable to expect that these issues would be discussed at legislative level - so that the pros and cons of legislative reform, and indeed of the technology itself, are considered in an open and politically accountable manner. "Radical" innovation (as compared with "incremental" innovation) is also associated with higher levels of scientific uncertainty and public contestation, ${ }^{24}$ and so, from a democratic perspective, there are compelling reasons for addressing such issues through the legislative procedure, rather than just at the executive level during the implementation of existing rules and regulations.

While there is a normative, democratic case to be made for radical innovation to be addressed through legislative process, in order to have open debate about difficult tradeoffs, policymakers might make strategic, discursive use of the incremental/radical distinction with quite the opposite effect. In other words, policymakers might perceive the socio-economic benefits of a technology as "radically" new, but describe the technology as "incrementally" innovative in technical terms, thereby avoiding the need for a new legislative framework that might otherwise stifle innovation. It can also be the case that risk-based regulation does less well at "seeing" or detecting incremental innovation, and so undervalues its significance. ${ }^{25}$

\section{2. "Radical" versus "incremental" innovation and evidence-based policymaking}

The distinction between "radical" and "incremental" innovation may also affect the evidence-base for policy and regulation, particularly the use of different evidencegathering tools and procedures. In the case of "incremental" innovation, it may often be enough to gather evidence via risk assessments at the executive stage of implementing existing legislation. Risk assessment is applied in areas involving exposures to potential harm, such as in fields chemicals or food regulation, where the development of new products and processes brings benefits but may also threaten the protection of public health or the environment. Risk assessment typically relies on scientific expertise gathered or institutionalised "independently", at a distance from the political arm of decision-making. Within the EU governance structure, risk assessment applies

23 E Stokes, "Regulating Nanotechnologies: Sizing Up the Options" (2008) 29(2) Legal Studies 281.

24 GC O'Connor and CM McDermott, "The Human Side of Radical Innovation” (2004) 21 Journal of Engineering and Technology Management 11.

25 See e.g. J Black and R Baldwin, "When Risk-Based Regulation Aims Low: Approaches and Challenges" (2012) 6(1) Regulation and Governance 2; Ford, supra note 4. 
predominantly in the day-to-day implementation of legislation, in situations where agencies and expert committees provide the Commission with independent scientific advice to decide, for example, whether to authorise a particular product or substance. Although such risk assessment - conducted at the executive level and predominantly techno-scientific in nature - may be sufficient for incremental innovation, radical innovation can pose bigger challenges to evidence-based policymaking.

Radical innovation is described as inhabiting a "high uncertainty" domain, ${ }^{26}$ and the greater the departure from existing technological products/processes (i.e. the more "radical" it is), the greater the potential unknowns and epistemic challenges. The product management literature, for example, shows that radically innovative products can be accompanied by increased uncertainty in four different respects: technical, market, organisational and resources. ${ }^{27}$ Increased uncertainty may also be seen in terms of health and environmental risks and socio-economic impacts. This poses obvious challenges in terms of evidence-gathering, but, given the EU's commitment to evidence-based decision-making, it must at least be arguable that the higher the levels of uncertainty, the greater the need to broaden the view of what constitutes "acceptable" evidence for regulatory action. In other words, high uncertainty invites policymakers to go the extra mile to gather information from a wider range of sources, to identify the main points of contention and to give a clearer indication of the nature and extent of the unknowns - not just those relating to technical risk, but also those stemming from the socio-economic complexity of innovation.

In EU governance, the obvious instrument to provide a wider evidence-base for policymaking is the integrated impact assessment (IIA). ${ }^{28}$ Since 2003 , the European Commission has operated a system of IIA aimed at assessing the economic, social and environmental impacts of all new legislative and major policy measures. Unlike risk assessments, IIAs are drafted by the European Commission itself, requiring the gathering of wider-ranging evidence, including that derived from consultation with stakeholders. This is particularly relevant when contemplating the regulation of technology that is "radically" innovative not only (or even mainly) in the techno-scientific sense, but also (or rather) as regards its socio-economic implications. In theory, at least, IIAs provide systematic means of assessing, on an equal basis, the likely economic, environmental and social implications - including but not just in terms of risk - and highlighting the main potential trade-offs involved in regulation. We recognise that the IIA is not perfect and raises its own set of questions, ${ }^{29}$ but under current arrangements it is the only formal procedure under which these broader trade-offs can be routinely made (e.g. between risks and wider socio-economic impacts, or between the objectives of risk management and innovation policy).

26 GC O'Connor and MP Rice, “A Comprehensive Model of Uncertainty Associated with Radical Innovation” (2013) 13 Journal of Product Innovation Management 2, 12.

27 ibid.

28 Although the two cannot be separated entirely, as the results of risk assessments can also feed into the IIA process (Commission, Better Regulation “Toolbox” (2015) Tool 12).

29 See e.g. J Torritia and R Löfstedt, "The First Five Years of the EU Impact Assessment System: A Risk Economics Perspective on Gaps Between Rationale and Practice" (2012) 15(2) Journal of Risk Research 169; S Smismans and R Minto, "Are Integrated Impact Assessments the Way Forward for Mainstreaming in the European Union?" (2016) Regulation and Governance, advance online publication: doi:10.1111/rego.12119. 
Hence, there is a normative argument for the regulation of radical innovation to rely not only on risk assessment but also on IIA, particularly if the application of risk assessment is otherwise limited to the day-to-day implementation of existing regulatory frameworks. Moreover, given the potentially significant consequences of radical innovation, it is arguably more appropriate to attempt to balance these considerations using an IIA at the legislative level so that the wider evidence-base can be fully debated. But while this may be normatively desirable in terms of evidence-based policymaking and democratic accountability, policymakers may in fact follow exactly the opposite strategy. By framing a technology as merely "incrementally" innovative, it becomes possible to narrow the evidence-base of policymaking. Such an approach, which may be characterised as deliberate non-knowing or "wilful regulatory ignorance", ${ }^{30}$ can be used to avoid the prospect of new legislation and thereby circumvent the need for an IIA.

\section{3. "Radical" versus "incremental" and the precautionary principle}

The distinction between "radical" and "incremental" innovation can also determine whether and how regulatory decisions are based on the PP. This relates to the question of evidence above. To understand how the defining of innovation as either "radical" or "incremental" may affect regulatory choices about the PP, we first need to take a closer look at the relationship between the PP and evidence. The PP enjoys pre-eminence in EU law, as a constitutional principle in the Treaty on the Functioning of the EU. ${ }^{31}$ Generally speaking, the principle requires decision-makers to be attuned to the problems caused by scientific uncertainty, and is used to justify regulatory action when supporting evidence is lacking. Yet its relationship with evidence-based policymaking is not self-explanatory. Some have even argued that the PP and evidence-based policy sit at opposite ends of the spectrum, and EU institutions have been accused of implementing the PP in ways that are "arbitrary and capricious" 32 and irrational. ${ }^{33}$ One of the criticisms is that the PP is "anti-science" because it encourages decisions based not on scientific fact but on unsubstantiated fear. ${ }^{34}$ But even a cursory inspection of relevant EU documents reveals that the PP does not provide a blank cheque for regulatory intervention ${ }^{35}$ and that evidence of some sort is needed before the principle is invoked.

While there are differing views on how much evidence is "enough" for the PP to apply, experience has shown that decisions in this context are approached in a highly rationalistic manner and kept within certain methodological limits. ${ }^{36}$ Rather than

\footnotetext{
30 For related discussion in the private sector, see D Michaels, "Manufactured Uncertainty: Contested Science and the Protection of the Public's Health and Environment", in RN Proctor and L Schiebinger (eds) Agnotology: The Making and Unmaking of Ignorance (Stanford University Press 2008) ch 4.

31 TFEU, Art. 191(2).

32 GE Marchant and KL Mossman, Arbitrary and Capricious: The Precautionary Principle in the European Union Courts (AEI Press 2004).

33 CE Sunstein, Laws of Fear: Beyond the Precautionary Principle (Cambridge University Press 2005); Government Office for Science, Annual Report of the Chief Scientific Advisor 2014 - Innovation: Managing Risk, Not Avoiding It (Government Office for Science 2014) 8.

34 Sunstein, ibid.

35 ACM Meuwese, Impact Assessment in EU Lawmaking (Kluwer Law International 2008) 89-91.

36 JF Whitehouse, "Will the Precautionary Principle Affect Environmental Decision-Making and Impact Assessment?" in R Harding and E Fisher (eds) Perspectives on the Precautionary Principle (Federation Press 1999) ch 3.
} 
dictating a particular outcome, the PP governs the process by which regulatory decisions are made. $^{37}$

At EU level, we can distinguish between "ex ante evidence" and "ex post evidence" dimensions of the PP. The ex ante dimension relates to the evidence policy makers have to provide when invoking the PP. First, the Commission notes that the PP "should be considered within a structured approach to the analysis of risk". ${ }^{38}$ Thus, a conditio sine qua non of the PP is risk assessment. Even if risks cannot be "fully" demonstrated by conclusive scientific evidence, the application of the PP requires at least some evidence of the reality and seriousness of the potential adverse effects. Risk assessment comprises hazard identification, hazard characterisation, appraisal of exposure and risk characterisation, and "[a]n attempt to complete as far as possible these four components should be performed before action is taken". ${ }^{39}$ Secondly, action taken on the basis of the PP should respond "proportionately" to the potential risk. ${ }^{40}$ What is "proportionate" will depend on the outcome of a cost-benefit analysis, by which the most likely consequences of action and inaction are compared. ${ }^{41}$ Importantly, the Commission states that cost-benefit analysis should be wide in scope and "other analysis methods, such as those concerning ... the socio-economic impact ... may also be relevant". 42 The more recent Better Regulation package of the Commission requires that a "proportionate impact assessment" has to be adopted whenever the PP is invoked. ${ }^{43}$ Although there is some legal ambiguity as to whether a "proportionate impact assessment" equates with a full IIA (i.e. triggering the corresponding requirements of an assessment of socio-economic and environmental impacts and particular forms of stakeholder consultation), it is clear that regulatory measures based on the PP cannot be adopted without any evidence. A series of procedural steps must be taken, including a risk assessment to make an initial calculation of the probability and magnitude of harm, and a proportionate impact assessment of the costs and benefits of the proposed action.

There is also an "ex post evidence" aspect to the PP, requiring additional evidencegathering exercises once a regulatory act based on the PP has been adopted. The idea is to ensure that decision-makers will go on to conduct a more detailed risk assessment than was possible when the regulation was introduced, and consider the need for regulatory revisions. According to the Commission, "[d]ecision-makers faced with an unacceptable risk, scientific uncertainty and public concerns have a duty to find answers". 44 Any risk management measure adopted on the basis of the PP should go "together with collection

\footnotetext{
37 E Fisher, Risk Regulation and Administrative Constitutionalism (Hart 2010); M Weimer, "Applying Precaution in EU Authorisation of Genetically Modified Products - Challenges and Suggestions for Reform" (2010) 16(5) European Law Journal 624.

38 Commission, "The Precautionary Principle" (Communication) COM (2000) 1 final, 2.

39 ibid Annex III.

40 ibid $17-18$.

41 Case T-70/99 Alpharma Inc v Council of the European Union [2002] ECR II-3495, para. 323.

42 Commission, supra note 38, para. 6.3.4. It is also important to note criticisms that cost-benefit analysis is a flawed method of decision-making, owing to problems of reductionism and incommensurability: see e.g. F Ackerman and L Heinzerling, "Pricing the Priceless: Cost Benefit Analysis of Environmental Protection" (2002) 150 University of Pennsylvania Law Review 1553; cf CR Sunstein, "Incommensurability and Valuation in Law" (1993) 92(4) Michigan Law Review 779.

43 Commission, Better Regulation "Toolbox" (Commission 2015), Tool 12.

44 Commission, supra note 38,3 .
} 
of additional evidence and review" 45 and should be "subject to review, in the light of new scientific data" and "capable of assigning responsibility for producing the scientific evidence necessary". ${ }^{46}$

The framing of innovation as "incremental" or "radical" can influence the role of the PP and its evidence dimensions in different ways. Given that "incremental" innovation is said to involve iterative change and is derivative of existing products and processes, it is often viewed as presenting low or "acceptable" risks and/or low uncertainty. As such, it may easily fall outside the scope of the PP, either because there is sufficient information available for appropriate preventive measures to be taken or because the desired level of health or environmental protection is not jeopardised. ${ }^{47}$ However, this implies a narrowing of the evidence base for decision-making. In the event that "incremental" innovation fails to trigger the PP (and hence a proportionate impact assessment), there is no formal, institutionalised ex ante method of analysing the broader socio-economic impacts as a matter of routine. Of course, there may be other, ad hoc ways of ensuring that the broader impacts of incremental innovation are taken into account (through for example, practices of Responsible Research and Innovation), ${ }^{48}$ but absent any expectation or obligation to do so, there is a danger that the wider setting of innovation its economic, environmental and social circumstances - will be overlooked.

If a technology is framed as "radical" in nature, it is more likely that the PP will be invoked, as it is associated with high or "unacceptable" risks and/or high uncertainty. In the event that the PP is applied, both its ex ante (risk assessment, impact assessment) and ex post (further data collection and periodic review) stages of evidence-gathering should come into play. However, even in cases of radical innovation, the evidential narrowness and lack of empirical ambition of the PP may still cause difficulties. As mentioned above, at the ex ante stage, the requirement to adopt a "proportionate impact assessment" when invoking PP is not necessarily the same as a requirement to conduct an IIA. Moreover, at the ex post stage, decision-makers are required to assign responsibility for producing the scientific evidence needed for a more comprehensive risk assessment, but there is no equivalent duty to continue to gather information on socio-economic considerations once the PP has been applied.

The overall effect is that broader concerns relating to innovation can receive short shrift (either because of a failure to trigger ex ante evidence-gathering or because ex post evidence-gathering operates within narrowly circumscribed limits). Although the framing of innovation as "incremental" or "radical" will help to determine whether the PP applies, that distinction could in fact be put to more worthwhile use. Scholars in science and technology studies and cultural studies have long called on decision-makers and policy actors to bridge the divide between techno-scientific and socio-economic risk analyses. ${ }^{49}$

45 Commission, Impact Assessment Guidelines. SE (2009) 92, Annex 12, 75.

46 Commission, supra note 38,3 .

47 ibid 7.

48 Commission, Options for Strengthening Responsible Research and Innovation (Commission 2013) ch 2.

49 B Wynne, "May the Sheep Safely Graze? A Reflexive View of the Expert-Lay Knowledge Divide" in S Lash, B Szerszynski and B Wynne (eds), Risk, Environment and Modernity (Sage 1996) ch 2; A Stirling, “'Opening Up' and 'Closing Down': Power, Participation, and Pluralism in the Social Appraisal of Technology" (2008) 33(2) Science, Technology and Human Values 262. In legal scholarship, see M Lee, "Risk and Beyond: EU Regulation of 
We contend that a more creative use of "incremental" and "radical" innovation types would represent an important step in that direction. Decisions on whether the PP will be invoked, and the evidence related to that, should start from the acknowledgement that a technical innovation can be radical or incremental for techno-scientific reasons and/or socio-economic reasons. A particular innovation may present a low or acceptable level of risk in techno-scientific terms ("incremental") but also wide-ranging and uncertain socioeconomic impacts ("radical"). Similarly, an innovation may pose a high or unacceptable risk and high uncertainty in techno-scientific terms ("radical") but be expected to have limited socio-economic implications ("incremental"). ${ }^{50}$ In the spirit if not the letter of the PP, either variation could prompt ex ante evidence-gathering and ex post efforts to gather further information on the full gamut of policy-relevant issues, including both techno-scientific and socio-economic concerns.

To summarise, the framing of a technology as "incremental" or "radical" may impact on the regulatory approach in several ways; namely, by influencing the desirability of legislative reform, the use of evidence-gathering tools and the application of the PP. Policymakers may make strategic use of framing innovation in one way or another to support their preferred regulatory solution. The categorisation of innovation as "incremental", for instance, can be used to avoid the high demands of evidence-based policymaking (or narrow its significance) or avoid new legislative action based on the PP. At the same time, the "incremental" versus "radical" divide, by acknowledging its dimensions along both the techno-scientific and socio-economic dimensions, could provide a more nuanced guide to the application of the PP, the choice of regulatory intervention and the evidence on which it is based.

We now turn to the example of EU nanotechnology regulation to show how ideas of "incremental" and "radical" innovation have come to frame not only the policy debate but also the regulatory responses in terms of legislative reform, evidence-gathering and the PP. To begin with, we give a brief introduction to nanotechnology and highlight the divergence of opinion as to its "innovativeness".

\section{NANOTECHNOLOGY: RADICAL BREAKTHROUGHS OR} INCREMENTAL IMPROVEMENTS?

"Nanotechnology" involves the creation or manipulation of materials at a tiny scale - the "nanoscale". 51 Nanomaterials have extremely small dimensions in the range 1-100 nanometres, one nanometre being one billionth of a metre. ${ }^{52}$ Materials are deliberately engineered at the nanoscale because they can have very different properties from their everyday equivalents. The capacity to produce materials with new and desirable properties has the potential to benefit many industrial and commercial sectors, and this potential is beginning to be realised.

(F'note continued)

Nanotechnology" (2010) 35(6) European Law Journal 799; EU Regulation of GMOs: Law and Decision Making for a New Technology (Edward Elgar 2008).

50 See F Haines, The Paradox of Regulation: What Regulation Can Achieve and What it Cannot (Edward Elgar 2011), especially on "actuarial" risk, as distinct from socio-cultural and political risk.

51 RS/RAEng, Nanoscience and Nanotechnologies: Opportunities and Uncertainties (RS and RAEng 2004) 5.

52 BSI, Vocabulary - Nanoparticles, Publicly Available Specification 71 (BSI 2011) 3. 
A good deal of attention is paid to the extent to which the products and processes of nanotechnology differ from those resulting from conventional means. Hotly debated are the possible applications of nanotechnology, as well as their potential risks and uncertainties. First, discussions of theoretically possible but currently unfeasible uses of nanotechnology tend to focus on its revolutionary nature and disruptive potential. ${ }^{53}$ Here, accounts may even stray into the realm of science fiction, such as that of Drexler who sees a role for nanotechnology in space colonisation: "Low-cost, lightweight, extremely strong materials would make transportation far more energy efficient and finally - make space transportation economical. The old dreams of expanding the biosphere beyond our one vulnerable planet suddenly look feasible once more". ${ }^{54}$ His more controversial claims include that "nanorobots ... could destroy viruses and cancer cells, repair damaged structures, remove accumulated wastes from the brain, and bring the body back to a state of youthful health". ${ }^{55}$ By any reckoning, those descriptions seem far-fetched, but especially when compared with more modest claims that current applications of nanotechnology "are actually incremental advances in well-developed areas of science". ${ }^{56}$ Others suggest that nanotechnology is seriously over-hyped, since "neither its ideas nor embodiment are entirely new" and "nanoscale science has been commonplace in biology and chemistry ... for many decades". 57

As such, there are conflicting views about the extent to which the ideas, methods or applications of nanotechnology are radically or incrementally new, and there is a limit to how far generalisations can be made about the technology - since "nanotechnology" is an umbrella term used to capture a huge variety of products and processes across diverse sectors and over different timeframes (i.e. present, near future, distant future). Such conflict is also apparent in debates about the potential risks associated with nanotechnologies. Although it is believed that some applications of nanotechnology "will present risks unlike any that we have encountered before", 58 there is disagreement about the degree to which those risks are new. Not all nanomaterials will be more hazardous than substances in their conventional form, but it is conceivable that some could cause unexpected interactions with the environment ${ }^{59}$ or human beings. ${ }^{60}$ After all, one of the attractions of nanotechnology is that it enables the engineering of nanomaterials that have new physical or chemical properties, and that exhibit behaviours quite unlike the same materials in bulk form. Concerns have been raised, therefore, that the very properties of nanomaterials that make them commercially so attractive could

\footnotetext{
53 S Wood, R Jones and A Geldart, The Social and Economic Challenges of Nanotechnology (ESRC 2003) ch 4.

54 KE Drexler, "Machine-Phase Nanotechnology" (16 September 2001), available at <http://www.ruf.rice.edu/ rau/ phys600/drexler.htm> (accessed 31 March 2017).

55 ibid.

56 DW Hobson, "Commercialization of Nanotechnology" (2009) 1(2) Wiley Interdisciplinary Reviews: Nanomedicine and Nanobiotechnology 189, 193.

57 D Loveridge, "Nanotechnology: its Potential as the 'Next Industrial Revolution' and its Social Consequences" (2002) Ideas in Progress Paper No 30, 2.

58 AD Maynard, Nanotechnology: A Research Strategy for Addressing Risk (Woodrow Wilson Center 2008) 6.

59 Royal Commission on Environmental Pollution, Novel Materials in the Environment: The Case of Nanotechnology (Cm 7468 2008) 14, 57.

60 M Kendall and S Holgate, "Health Impact and Toxicological Effects of Nanomaterials in the Lung" (2012) 17(5) Respirology 743.
} 
potentially pose unforeseen risks. ${ }^{61}$ Whether those properties produce "radically" or "incrementally" different risk profiles rather depends on the context in which such a determination is made. ${ }^{62}$

But while one might speculate about the unusual properties and toxicity of certain nanomaterials, they can in some circumstances be difficult to characterise with precision. And while initial evidence suggests that certain nanomaterials, in certain exposure scenarios, may present an increased hazard, it is not always clear what this means in terms of risk - because of gaps in technical data or a lack of applicable test methods. ${ }^{63}$ This may be thought of as uncertainty in the "straightforward" sense of incomplete information, which, it is presumed, can be overcome by closing knowledge gaps and developing suitable metrics - in other words, by "doing more science". But uncertainty also exists in relation to the "non-technical" aspects of nanotechnology, given that there has been relatively little evidence-gathering on issues such as the public acceptability of the technology and its various applications. As the science and technology studies literature has shown, the "facts" about a technology are multi-faceted, and often highly contested and inconclusive - certainly in the early stages of the technology's emergence. ${ }^{64}$ This presents significant challenges for policymakers, especially since regulation is expected to be based on clear evidence and "sound science". 65

From this we can note that a technology may be regarded as an "incremental" development in some ways but a "radical" departure in others. For example, its potential risks may be seen as a mere continuation of those associated with existing technological products/processes, and yet in terms of uncertainty and contingency it may be deemed to be socially, economically and/or materially different. This separating out of the risks from the broader effects is evident in the case of nanotechnology, where emphasis is on both the evolutionary ("incremental") nature of potential harms and the revolutionary ("radical)" promise of far-reaching benefits. Take, for instance, the application of nanotechnology to the chemical and pharmaceutical industries. While techniques of nanotechnology in these sectors are described as "another incremental advance in nanoscale science", their broader impact on the economy and society "may be substantial". 66

So there is no easy answer to the question, is nanotechnology "radically" or "incrementally" innovative? Much depends on the focus, perspective and indeed imagination of the observer. Given the fluidity and constructedness of the boundaries between different innovation "types", one might well conclude that such a division has little normative force. And yet, we find the categorisation at the very heart of the EU's regulation of nanotechnology. Even though the EU institutions rarely use the terms

\footnotetext{
61 AD Maynard, "Safe Handling of Nanotechnology" (2006) 444 Nature 267, 267.

62 MD Maynard, "Is Novelty Overrated?" (2014) 9 Nature Nanotechnology 409.

63 SCENIHR (2007) Opinion on the Appropriateness of the Risk Assessment Methodology in Accordance with the Technical Guidance Documents for New and Existing Substances for Assessing the Risks of Nanomaterials, adopted at the 19th plenary on 21-22 June 2007; OCED, Report of the OECD Expert Meeting on the Physical Chemical Properties of Manufactured Nanomaterials and Test Guidelines (OECD 2014).

64 See e.g. WE Bijker, TP Hughes and T Pinch (eds), The Social Construction of Technological Systems (MIT Press 1987); A Feenberg, Transforming Technology: A Critical Theory Revisited (Oxford University Press 2002).

65 S Jasanoff, "Procedural Choices in Regulatory Science" (1995) 17 Technology in Society 279.

66 Wood, Jones and Geldart, supra note 53, 5.
} 
"incremental" and "radical", these ideas carry important political and strategic implications. Indeed, the question of whether nanotechnology is radical or incremental in nature, while unsatisfactory in many regards, has had a pivotal role in constructing regulatory responses. Here we find that the European Commission and the European Parliament have taken very different stances on the "innovativeness" of nanotechnology, which is in turn reflected in their polar opposite positions on the nature and extent of evidence-based regulation in this context.

\section{The European Commission And the Regulation of "INCREMENTAL" INNOVATION}

Let us start with the European Commission's characterisation of nanotechnology as "incremental" innovation, and examine how this characterisation has resulted in an approach to regulation based on existing legislation, evidence-gathering at the executive level, a lack of active engagement with the PP and an avoidance of IIA. The Commission is of the view that new applications of nanotechnology fall squarely within the remit of existing regulations, notwithstanding that the regulations were introduced long before applications of nanotechnology became commercially available and viable. ${ }^{67}$ Existing regulations are broad in scope and establish general, technology-neutral standards of health and environmental safety, and there is no shortage of regulatory coverage in sectors in which nanotechnology is currently used (such as chemicals, foods, medicines and cosmetics). The General Product Safety Directive, for instance, requires manufacturers and suppliers to ensure that their products are safe before being placed on the EU market. ${ }^{68}$ With limited exceptions, the Directive covers all products intended for, or likely to be used by, consumers, and it does not distinguish between products of different technological origin and/or material size. Sectorspecific legislation imposes similarly generic standards of safety. The General Food Law, for example, stipulates that food "shall not be placed on the market if it is unsafe". ${ }^{69}$ It applies to all food products, whether or not they contain nanomaterial ingredients.

It is worth noting that many of these existing legislative measures contain references to or are based on the PP. The General Food Regulation provides that, where harmful effects on health have been identified through scientific assessment, but scientific uncertainty persists, a Member State may adopt provisional risk management measures based on the PP until further scientific information becomes available. ${ }^{70}$ So engagement with the PP occurs if and when a Member State chooses to adopt a risk management measure on this basis - although outside these confines, the PP features little in the Commission's discussion of nanotechnology regulation. On the application of chemicals regulation to nanotechnology, for example, the Commission has noted that the relevant legislation is already underpinned by the PP. ${ }^{71}$ In other words, the Commission adopts a

67 Commission, "Regulatory Aspects of Nanomaterials" (Communication) COM (2008) 366 final, 3; "Second Regulatory Review of Nanomaterials" (Communication) COM (2012) 572 final, 11.

68 European Parliament and Council Directive 2001/95/EC on general product safety [2002] OJ L11/4, Art. 3.

69 European Parliament and Council Regulation (EC) No 178/2002 laying down the general principles and requirements of food law [2002] OJ L31/1, Art. 14.

70 ibid Art. 7.

71 Commission, "Regulatory Aspects of Nanomaterials", supra note 67, 4. 
deferential approach, meaning that discussion of the PP is limited to observations that the principle is already enshrined in EU product legislation. Its usage is thus confined to the implementation stage of existing legislative measures and individual executive decisions - either by Member States where market entry is regulated at national level, or by the Commission assisted by comitology where regulatory decision-making is centralised.

Given that existing regulations are broad in remit, establish generic standards of safety and take into account the PP, the Commission has concluded that "current legislation covers to a large extent risks in relation to nanomaterials and that risks can be dealt with under the current legislative framework". ${ }^{72}$ In other words, the Commission sees no need for substantive legislative reform. Nanotechnology does not present "radically" different risks such that it necessitates new legislative provisions. Instead, the Commission approaches nanotechnology as "incremental" innovation that can be dealt with under existing regulatory regimes. It is interesting that the scope and content of existing regulatory measures should inform understandings of technological novelty like this. ${ }^{73}$

Such framing has important implications for the evidence gathered in the policymaking process. Because it has not presented any new legislative or major policy initiatives to deal with nanotechnology - preferring instead to rely on existing regulations - the Commission has not undertaken any IIAs on the issue (with one exception). ${ }^{74}$ This does not mean a complete absence of evidence-gathering in EU policymaking on nanotechnology. Rather, it means that evidence-gathering has taken place predominantly in the application of the existing regulatory regimes, by way of scientific assessment at the executive level. There are numerous examples of this. For instance, the Commission's scientific committees have published several opinions on consumer safety, public health and environmental issues associated with nanotechnologies generally. The former Scientific Committee on Emerging and Newly Identified Health Risks has issued opinions on matters such as the risk assessment of products of nanotechnologies ${ }^{75}$ and on the appropriateness of methodologies for testing the potential risks of nanotechnologies. ${ }^{76}$ The scientific committees have also produced a series of ad hoc risk assessments for specific applications of nanotechnology. For example, the former Committee on Consumer Safety has published risk assessments for the use of nanoscale titanium dioxide ${ }^{77}$ and carbon black ${ }^{78}$ in cosmetic products.

72 ibid 3 .

73 Jasanoff, supra note 3.

74 Note that the Commission has introduced two new implementing acts that mention "nanoparticles" and substances in "nanoform" (Commission Regulation (EC) 450/2009 on active and intelligent materials and articles intended to come into contact with food [2009] OJ L 135/3; Commission Regulation (EU) 10/2011 on plastic materials and articles intended to come into contact with food [2011] OJ L 12/1); however, neither measure was subject to IIA and both were designed to facilitate the implementation of the existing regulatory regime. For excellent discussion, see T Ehnert, Regulating the Invisible: A Critical Analysis of the EU's Approach to Nanotechnologies (Maastricht University Centre for European Law 2015). For the exception, see Commission, "Impact Assessment on the Revision of the Regulatory Framework for Medical Devices" (Staff Working Document) SWD (2012) 273 final.

75 SCENIHR, Risk Assessment of Products of Nanomaterials, adopted at its 28th plenary on 19 January 2009.

76 SCENIHR, supra note 63.

77 SCCS, Opinion on Titanium Dioxide (Nano Form), adopted by written procedure on 22 July 2013.

78 SCCS, Opinion on Carbon Black (Nano Form), adopted at 4th plenary meeting of 12 December 2013 (revised on 27 March 2014 and 15 December 2015). 
Other opportunities for evidence-gathering arise under the sector-specific legislation. For instance, the Community Action Rolling Plan under EU chemicals legislation specifies which chemical substances are to be subject to in-depth evaluation. Member States contribute to the development of the Community Action Rolling Plan by proposing chemical substances for inclusion. A number of Member States have initiated substance evaluation activities for various nanomaterials: for example, the Netherlands has proposed the evaluation of nanomaterial silicon dioxide, due to concerns about the characterisation and toxicity of nanoparticle-forms of the substance, ${ }^{79}$ and Germany has singled out multi-walled carbon nanotubes because of concerns about possible risks posed to consumers and workers. ${ }^{80}$ Under that procedure, the Competent Authority in the respective Member States will evaluate the substance before preparing a draft decision or conclusion document (depending on the sufficiency of available information).

Several points are worth noting. One is that the evidence gathered during these processes relates to issues of science. Scientific input is, of course, essential to evaluating the risks involved in applications of nanotechnology, even if it is not the only source of policy-relevant knowledge. A cursory survey of the evidence-gathering exercises on nanotechnology reveals that an overwhelming majority of them are focused on the technical aspects of regulation nanotechnology, such as how to assess the risks of nanomaterials already covered by EU regulation. Much less attention has been paid to the broader types of information that would normally be collected and analysed through IIA. That is not to say that there is no room for considering broader socio-economic factors. For instance, provision is made under the REACH Regulation for certain decisions, in certain circumstances, to take into account the socio-economic implications of authorising or not authorising a chemical substance ${ }^{81}$ - however, the limited scope of the provision means that it is not routinely engaged. As a result, the approach taken to the socio-economic aspects of nanotechnology may be described as ad hoc rather than principled. Moreover, by concentrating its efforts on regulatory implementation (rather than on legislative reform, which would automatically be subject to an IIA), the Commission bypasses broader questions about the direction of technological progress, the public acceptability of the risks involved, and the fair distribution of costs and benefits.

For the purpose of regulation, the Commission's characterisation of nanotechnology as "incremental" innovation is based on techno-scientific claims of risk. When dealing with research and innovation policy, however, the Commission's framing of nanotechnology is rather different. There the Commission underlines the radical potential of nanotechnology, describing it as a "key enabling technology" in the EU's quest to achieve a highly innovative, knowledge-based economy. ${ }^{82}$ According to its strategy for the "Innovation Union", nanotechnology will play a key role in the EU's

\footnotetext{
79 ECHA, Nanomaterials and REACH: Eighth Stakeholders' Day (ECHA 2013).

80 ECHA, Justification for the selection of a substance for CoRAP inclusion: Multi-Walled Carbon Nanotubes (MWCNT), synthetic graphite in tubular shape (ECHA undated).

81 Regulation (EC) No 1907/2006 of the European Parliament and of the Council of 18 December 2006 concerning the Registration, Evaluation, Authorisation and Restriction of Chemicals (REACH) [2006] OJ L396/1, Art. 60(4).

${ }^{82}$ Commission, "Preparing for Our Future: Developing a Common Strategy for Key Enabling Technologies in the EU" (Communication) COM (2009) 512.
} 
expanding markets and increased global competitiveness. ${ }^{83}$ The Commission notes that nanotechnology has "huge commercial potential" and that "the potential of nanotechnology to do good, or at least to make a profit, is clearly immense". 84 Nanotechnology is said to hold "the promise of leading to the development of smart nano and micro devices and systems and to radical breakthroughs in vital fields such as healthcare, energy, environment and manufacturing". 85 Moreover, the Commission describes nanotechnology as having "revolutionary impact" in materials science, information and communications technology, life sciences and consumer products "once the research is translated into breakthrough products and production processes". 86

The Commission concludes that "scientists and businessmen are unanimous: nanotechnology is much more than just a new 'hype",. ${ }^{87}$ This supports a particular vision of nanotechnology - as offering a great deal of promise - while downplaying complexity, uncertainty and controversy. ${ }^{88}$ Yet general claims about the benefits of nanotechnology are supported by little evidence, and no serious attempts have been made to hold them to account. Although the IIA is one forum in which the weighing-up, trading-off and balancing of competing claims could take place, this option has not been pursued as a matter of course.

Whereas the Commission makes broad claims about the "radical" benefits of nanotechnology in the context of innovation policy, it approaches the issue of regulation as involving "incremental" innovation governable by existing legislation and at the executive level of risk assessment. By deploying arguments of "mere incremental change", the Commission employs a strategy of "deliberate regulatory ignorance" 89 and avoids having to establish a broader evidence base or conduct democratically accountable debate to provide reasons for its regulatory choice. One might wonder whether the Commission's approach has been influenced by previous regulatory controversies involving technological innovation, such as the cultivation and marketing of genetically modified organisms (GMOs). The Commission has been heavily criticised for its handling of GMO regulation, ${ }^{90}$ and it is understandable that it would want to avoid similar reproach by downplaying the need for more extensive scrutiny in the context of nanotechnology.

\footnotetext{
83 Commission, "Europe 2020 Flagship Initiative Innovation Union" (Communication) COM (2010) 546 final.

84 Commission, Nanotechnology: Innovation for Tomorrow's World (Commission 2004).

85 Commission, "Proposal for a Regulation of the European Parliament and of the Council establishing Horizon 2020 - The Framework Programme for Research and Innovation (2014-2020)" (Communication) COM (2011) 809 final, para. 1.2.2.

86 Commission, "Second Regulatory Review on Nanomaterials", supra note 67, 46.

87 Commission, supra note $84,46$.

88 Of course, the same holds for generalisations in the other direction, i.e. warnings of the risks of nanotechnology as if nanotechnology were a single type of technology. For discussion, see GA Hodge GA, DM Bowman and AD Maynard, "Introduction: The Regulatory Challenges for Nanotechnologies" in GA Hodge, DM Bowman and AD Maynard (eds) International Handbook on Regulating Nanotechnologies (Edward Elgar 2010) 7.

89 See also WE Wagner, "Commons Ignorance: The Failure of Environmental Law to Produce Needed Information on Health and the Environment" (2004) 53(6) Duke Law Journal 1619; JY Zhang, C Marris and N Rose, The Transnational Governance of Synthetic Biology: Scientific Uncertainty, Cross-Borderness and the "Art" of Governance (Centre for the Study of Bioscience, Biomedicine, Biotechnology and Society, LSE 2011).

90 On the political and legal conflicts, see G Skogstad, "Contested Accountability Claims and GMO Regulation in the
} European Union” (2011) 49(4) Journal of Common Market Studies 895. 


\section{Regulating “RAdicAL” InNOVATION AND the ResPonse OF THE EUROPEAN PARLIAMENT}

So far we have shown how, in formulating its regulatory response, the Commission has characterised nanotechnology as a type of "incremental" innovation that does not require new legislation, IIA or additional engagement with the PP. By contrast, the European Parliament has approached nanotechnology as an example of "radical" innovation in need of legislative reform (and hence an accompanying IIA) based on the PP. So, unlike the Commission, which has interpreted nanotechnology as adequately covered by existing legislative frameworks, the Parliament does not accept that existing regulations are fit for purpose. ${ }^{91}$

The Parliament's Environment Committee has been especially critical of the Commission for providing only a general overview of existing legislation and for failing to consider the specific properties, uses, risks and benefits of nanotechnology. For example, it once remarked that "the Commission's analysis is based on a onedimensional, legalistic overview of the current rules but those rules are about as effective in addressing nanotechnology as trying to catch plankton with a cod fishing net". ${ }^{92}$ It said it "deplores the absence of a proper evaluation of the de facto application of the general provisions of Community law in the light of the actual nature of nanomaterials", ${ }^{93}$ and disagreed with the Commission's view that the full implications of nanotechnology were appropriately covered ${ }^{94}$ In its Resolution on the matter, the Parliament highlighted that "nanomaterials have the potential to bring about far-ranging societal change", 95 and "[c]alls on the Commission and Member States to pay special attention to the social dimension of the development of nanotechnology" ${ }^{96}$ It went on to argue that nanomaterials should be treated as "new" substances under existing regulation, so that they would be assessed separately from conventional types of material. ${ }^{97}$ Moreover, the Parliament has called for "nano-specific amendments to relevant horizontal and sectoral legislation". 98

Such an approach is based, at least in part, on the idea that legislative amendment is justified on grounds of the PP. For example, the European Parliament has argued that nanomaterials "should be covered by a multi-faceted, differentiated and adaptive body of law based on the precautionary principle", citing the Commission's earlier Communication on the Precautionary Principle as a reason for introducing new legislative provision. This stands in contrast with the Commission's approach to nanotechnology, which is premised on the idea that the PP is already operative under the EU acquis.

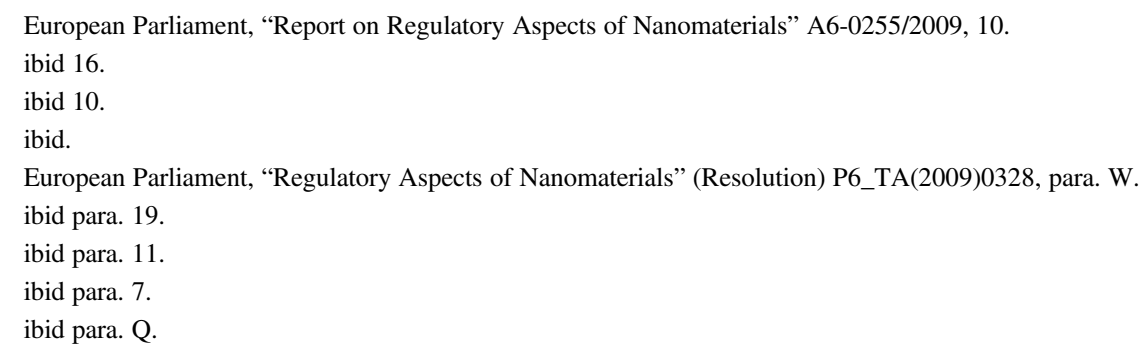


This illustrates how different ideas about the role and functioning of the PP can rest on different conceptions of innovation.

One might expect from the foregoing that the European Parliament's opposite stance on nanotechnology would also open up the possibility of IIAs, based on engagement with the PP. Yet the situation is not so straightforward, and it is important to remember that any discursive framing of innovation types takes place against a complex legal and political backdrop. Although the Parliament perceives nanotechnology to be at the "radical" end of the innovation spectrum (having the potential to effect "far-ranging societal change"100 and requiring at least some consideration of a dedicated legal framework), its limited institutional powers mean that it cannot draft new legislation on the matter. Instead, new legislation depends on the initiative of the Commission - which, as shown above, has not been forthcoming.

To overcome this practical difficulty, the Parliament has adopted a strategy of tabling nano-specific amendments whenever existing legislation comes up for periodic review by the Commission. ${ }^{101}$ During periodic review, the Commission has proposed various revisions to measures of existing legislation but none of its proposals (with one exception, discussed below) has made any reference to "nanomaterials" or "nanotechnology". The European Parliament, during its first or second readings of the Commission's proposals, has inserted nano-specific provisions to the legislative text. Through this approach, it has succeeded in introducing legislative requirements for nanotechnology in sectors of food, ${ }^{102}$ cosmetic products, ${ }^{103}$ electrical and electronic equipment, ${ }^{104}$ and biocidal products. ${ }^{105}$ For example, authorised biocidal products containing nanomaterials must now carry a label listing all nanomaterial ingredients, followed by the word "nano" in brackets. ${ }^{106}$ Cosmetic products containing nanomaterials must similarly be labelled, and be notified to the Commission before being placed on the market. ${ }^{107}$ So just as the Commission has used arguments of "incremental" innovation to justify the legislative status quo, so too has the European Parliament relied on claims of "radical" innovation to instigate legislative change.

Following this line of thought, it seems reasonable to suppose that the European Parliament's approach would also have resulted in more systematic engagement with the PP through the use of ex ante and/or ex post gathering and analysis of evidence. Curiously enough, though, the Parliament has failed to carry out any impact assessment - in spite of its criticisms of the Commission for neglecting the wider implications of

\footnotetext{
100 European Parliament, supra note 95.

101 RG Lee and E Stokes, "Material Uncertainty: Nanomaterials, Regulation and Symbolic Legislation" in B van Klink, B van Beers and L Poort (eds) Symbolic Legislation: Theory and Developments in Biolaw (Springer 2016) ch 13.

102 European Parliament and Council Regulation (EU) No 1169/2011 on the provision of food information to consumers [2011] OJ L304/18, Arts. 2(2)(t), 18(3).

103 European Parliament and Council Regulation (EC) No 1223/2009 on cosmetic products [2009] OJ L342/59, Arts. 13(1)(f), 16, 19(1(g).

104 European Parliament and Council Directive (EU) 2011/65 on the restriction of the use of certain hazardous substances in electrical and electronic equipment [2011] OJ L174/88, Preamble 16.

105 European Parliament and Council Regulation (EU) No 528/2012 on biocidal products [2012] L167/1, Arts. 3(1)(z), 3(3), 3(4), 4(4), 19(1)(f), 25(c), 58(3)(d), 65(3)(d), 69(2)(b).

106 ibid Art. 69(2)(b).

107 Regulation (EC) No 1223/2009, supra note 103, Art. 13(1)(f).
} 
nanotechnology regulation. It transpires that the way in which the regulatory framework evolved has important consequences for the evidence on which it is based. Since the nano-specific amendments were introduced by the Parliament, none were subject to an IIA by the Commission. At the same time, however, the European Parliament failed to live up to its commitment to adopt its own impact assessment on any substantive amendments that it proposes. Such a commitment was made in the 2003 Interinstitutional Agreement on Better Law-making ${ }^{108}$ and the 2005 Interinstitutional Common Approach to Impact Assessment, ${ }^{109}$ and is repeated in the new Interinstitutional Agreement on Better Law-Making proposed in 2015. ${ }^{110}$ Yet none of the Parliament's amendments concerning nanotechnology have been accompanied by an impact assessment. This suggests one or a combination of things; the Parliament might not have conceived of its amendments as "substantive", or it might not have had the time or resources to devote to an impact assessment. ${ }^{111}$ Whatever the case may be, it suggests that arguments of "radical" innovation have justificatory force - in the same way that arguments of "incremental" innovation have justificatory force, albeit in the opposite direction - but their normative and methodological (i.e. evidence-gathering) implications need to be more carefully worked through.

The result is that the newly-amended regulatory framework now applicable to nanotechnology has a thin evidence base. One way of redressing this would be to require a more explicit treatment of the different dimensions of innovation - techno-scientific and socio-economic - and a more liberal reading of the PP, so that scientific uncertainty and potentially significant effects in either dimension would prompt further evidencegathering and evaluation. We have seen above how decision-makers can have a tendency to deal with one dimension or the other in matters of regulation (the Commission with the techno-scientific aspects; and the European Parliament with the socio-economic concerns). In order to ensure that both receive due attention, and so that future legislative amendment on nanotechnology is subject to (or more seriously considered for) IIA as a matter of routine, it is important to ensure that techno-scientific and socio-economic considerations are both built into processes for regulating innovation.

\section{Conclusion}

In this article, we have explored the concept of innovation to show the importance of nuance in thinking about regulatory responses, and to highlight both the strategic and normative force of particular innovation "types". By relying on a broader innovation literature, and taking our cue from studies of biotechnology ${ }^{112}$ and

\footnotetext{
108 European Parliament, Council, Commission (2003) Interinstitutional Agreement on Better Law-Making [2003] OJ C321/1, para. 30 .

109 European Parliament, Council, Commission, Inter-Institutional Common Approach to Impact Assessment, available at <http://ec.europa.eu/smart-regulation/better_regulation/documents/ii_common_approach_to_ia_en.pdf>, para. 14 (accessed 31 March 2017).

110 Commission, "Proposal for an Interinstitutional Agreement on Better Regulation" (Communication) COM (2015) 216 final, para. 10.

111 T Ehnert, Regulating the Invisible: A Critical Analysis of the EU's Approach to Nanotechnologies (Maastricht University Centre for European Law 2015); The Legitimacy of New Risk Government - A Critical View in Light of the EU's Approach to Nanotechnologies in Food" (2015) 21(1) European Law Journal 44.

112 Jasanoff, supra note 3 .
} 
financial products regulation, ${ }^{113}$ we have distinguished between "radical" and "incremental" innovation and assessed the implications of this distinction for EU regulatory policy. Acknowledging that the distinction is not clear-cut but a question of degree, we have argued that whether one is dealing with "radical" or "incremental" innovation may have an impact on the choice of regulatory framework, the use of the PP, and the nature and extent of the evidence-base. The case study of nanotechnology regulation shows how the distinction has played out in practice in this particular field.

The EU's regulatory approach to nanotechnology is characterised by a tension between the Commission, which approaches the issue as one of "incremental" innovation, and the European Parliament, which sees nanotechnology in more "radical" terms. Although the Commission makes broad and often unsubstantiated claims about the radical socio-economic potential of nanotechnology, its regulatory approach has focused on nanotechnology as necessitating the risk regulation of incremental innovation. As a result, evidence-gathering has tended to be confined to processes of risk assessment conducted in the implementation of existing, generic legislation. As a consequence, the evidence-base of policy on nanotechnology is thin as it only provides information on the application of non-specific legislative frameworks and through the risk assessments underpinning executive decisions, which do not involve the routine gathering of broader information as would be expected of IIA. While the Parliament has managed to insert nano-specific provisions into existing legislation, it too has failed to add much to the evidence base of the regulatory framework. As a result, and notwithstanding claims about the socio-economically, "radically" innovative nature of nanotechnology, the regulatory approach is characterised by a paucity of evidence about the social, economic and environmental aspects of nanotechnology and only limited engagement with the PP. This approach is regrettable for several reasons: it does not allow for trade-offs between narrowly-defined risks and wider socio-economic impacts (or a more substantive use of the PP in this regard), nor does it promote open discussion of the careful balance between risk regulation in a narrow sense and other policymaking objectives. Moreover, by framing nanotechnology as "incremental" innovation and confining evidence-gathering to the level of risk assessment at the implementation stage, the Commission has bypassed a more broadly informed and more democratic debate on the issue.

While the regulatory literature has generally paid little attention to the strategic uses of "innovation", policymakers are actively involved in conceptualising innovation in order to frame regulatory approaches and justify regulatory choices. The conceptualisation of innovation can therefore be understood as an important device in the discursive politics of regulation. In our case study, the approach of the Commission to frame nanotechnology as "incremental" is unlikely to be unintentional. Faced with the uncertainty of radical innovation, a strategy of "deliberate regulatory ignorance" - enabled by framing the issue as merely incremental - might prove an attractive means of avoiding public and political conflict that could stifle innovation. It is doubtful that this approach is unique to nanotechnology. The Commission's approach in this particular instance is perfectly understandable, however it is disappointing from a normative perspective.

113 Ford, supra note 4. 
The label "incremental" should not be an excuse to limit exercises in evidence-gathering and avoid broader debate. On the contrary, it could even be argued that public policymaking institutions should be more willing to go the extra mile by gathering all possible information and allow a democratic debate on innovation that has potentially wide social, economic, health and environmental impacts. Recognising that innovation can be "radical" or "incremental" along different dimensions (techno-scientific and socio-economic) may help to structure the inclusion of more nuanced considerations about legislative reform, the use of $\mathrm{PP}$, and requirements of evidence-based policymaking. 